\title{
ANALISIS EXTERNAL FACTOR EVALUATION (EFE) MATRIX DAN INTERNAL FACTOR EVALUATION (IFE) MATRIX PADA MASTERPIECE FAMILY KARAOKE KOTA BENGKULU
}

\author{
Meiffa Herfianti ${ }^{1}$ \\ E-mail : meiffaherfianti@gmail.com \\ Sulisti Afriani ${ }^{2}$ \\ E-mail : sulistiafriani@gmail.com \\ Berian Saputra ${ }^{3}$ \\ E-mail : berian@gmail.com
}

\section{UNIVERSITAS DEHASEN BENGKULU}

\begin{abstract}
Masterpiece family karaoke Bengkulu city, is one of the industry focusing in family entertainment by presenting adequate facilities and services and more practical karaoke system, also sell a variety of food and beverages and various promotional packages, the use of play songs play store applications Masterpiece KTV through mobile phones. This study aim is to determine the analysis of external and internal matrix in Masterpiece family karaoke Bengkulu city. Data collection methods in this study is to use questionnaires by giving questions to the 75 respondents. The analytical method used is an external internal matrix. From the calculation of external internal strategy factor, it is obtained that internal strategy factor score of 3.89 and total external factor strategy score of 3.87. From the results of this study masterpiece family karaoke city Bengkulu lies in cell 1 by using growth strategy that is growth and concentration through vertical integration. Growth strategy with vertical integration is a strategy done by expanding the company by taking over the function of the supplier or taking over the distributor's function.
\end{abstract}

\section{Keywords: Marketing Strategy, External Internal Matrix Analysis}

\section{PENDAHULUAN}

Perusahaan didirikan dengan tujuan untuk menghasilkan laba agar perusahaan mampu bertahan ditengah ketatnya persaingan dan dapat memberikan inovasi agar produk perusahaan yang ditawarkan dapat diterima konsumen. Semakin ketatnya tingkat persaingan dibutuhkan fungsi pemasaran yang baik, sehingga tujuan yang diharapkan oleh perusahaan akan tercapai, karena pemasaran merupakan pilar utama yang penting dalam kelengkapan hidup perusahaan. Menurut Rangkuti (2015:178) setiap perusahaan yang unggul adalah mereka yang mampu menghadapi berbagai macam bentuk persaingan dari perusahan-perusahan yang sejenis baik itu pesaingan dalam bentuk produk, harga, dan kualitas, yang mengakibatkan masyarakat lebih efektif dalam memilih kualitas pelayanan yang akan dibelinya. Untuk menjaga kelangsungan hidup 
perusahaan harus dapat menyesuaikan pasar, oleh sebab itu suatu perusahaan harus mengetahui perubahan lingkungan yang terjadi, karena hal tersebut sangat penting untuk menentukan strategi yang akan diterapkan untuk mencapai tujuan perusahaan, sehingga di perlukan perencanaan yang matang dalam mencapai tujuan tersebut.

Tingkat persaingan terjadi antar perusahaan tak lepas dari strategi pemasaran yang diterapkan, baik dalam usaha pengenalan produknya maupun usaha merebut pasar (konsumen). Hal ini di lakukan perusahaan agar penjualan dapat meningkat dan kelancaran usaha dapat terjamin. Tidak ada suatu perusahaan yang mampu bertahan, jika perusahaan tersebut tidak mampu memasarkan barang dan jasa yang dihasilkan maka perusahaan tersebut tentu akan mengalami kebangkrutan. Namun sebaliknya, jika perusahaan mampu meningkatkan penjualan, maka perusahaan tersebut mempunyai kemungkinan untuk melanjutkaan usahanya. Dalam memasarkan produknya perusahaan harus bisa menerapkan strategi pemasaran yang dijadikan tindakan atau arah, keinginan perusahaan dalam menjalankan aktivitasnya. Tujuan utama perencanaan strategi agar perusahaan dapat melihat secara obyektif kondisi-kondisi internal dan eksternal sehingga perusahaan dapat mengantisipasi perubahan lingkungan eksternal. Matrik internal-eksternal ini dikembangkan dari model General Electric (GE-Model). Parameter yang digunakan meliputi parameter kekuatan internal perusahaan dan pengaruh eksternal yang dihadapi. Tujuan penggunaan model ini adalah untuk memperoleh strategi bisnis di tingkat yang lebih detail.

Masterpiece family karaoke merupakan salah satu indsutri di bidang hiburan keluarga yang menghadirkan konsep nasionalisme didalamnya konsep unik ini lahir dari konsep AHMAD DHANI seorang pianor music yang terkenal akan kecintaannya pada Indonesia. Visi yang ia miliki telah mengunggahnya untuk menghadirkan sebuah hiburan keluarga terbaik. Nama masterpiece ini diciptakan langsung oleh AHMAD DHANI dengan arti maha karya nama keberuntungan ini telah membuatnya mendapatkan keuntungan yang sangat besar pada akhirnya para pembisnis usaha melakukan kerja sama oleh AHMAD DHANI. Masterpiece family karaoke telah di didirikan 35 outlet salah satunya kota bengkulu grand opening diresmikan oleh seorang musisi ahmad dhani pada hari minggu tanggal 20 maret 2016 di kota bengkulu pada hari minggu, perusahaan ini mampu bersaing dengan usaha yang lain memiliki unggul dalam desain interior masterpiece family karaoke juga menghadirkan keunggulan sound system yang mampu menghadirkan suara yang jernih, monitor touchscreen, wireless keyboard, TV Led, menyediakan berbagai macam jenis ruangan, jenis-jenis makanan, dan minuman. Dalam memasarkan produknya, masterpiece kota bengkulu selama ini menerapkan strategi seperti meningkatkan kualitas pelayanan, memberikan produkproduk yang berkualitas dan mempertahankan kepercayaan konsumen sehingga perusahaan masterpiece family karaoke kota bengkulu mampu bersaing dengan perusahaan sejenis.

Semakin banyak dan semakin canggihnya sarana hiburan pada saat ini semakin banyak pula pesaing dalam memberi kualitas dan semakin banyak pula pesaing meniru hak cipta yg telah dimiliki maka dari hal tersebut masterpiece Bengkulu melakukan system dengan kecanggihan teknologi melakukan hak merek disetiap pemutaran lagu dalam 
system karaoke serta alat sound system yg lebih praktis. Meningkatnya sarana hiburan masterpiece kota bengkulu yang menguasai pasar dalam pembuatan system karaoke semua lagu yang bisa dinyanyikan oleh Costumer masterpiece family karaoke bengkulu dengan jumlah mencapai ratusan pelanggan. Jika dilihat dari segi penjualan produkproduk pada masterpiece family karaoke khususnya kota bengkulu di semua kalangan mulai dari anak-anak muda sampai dewasa. Berdasarkan latar belakang yang dilakukan oleh masterpiece family karaoke kota bengkulu dalam menghadapi pasar dan memasarkan produk-produknya. Sehingga penulis tertarik mengambil judul "Analisis external factor evaluation(EFE) matrix dan internal factor evaluation matrix pada masterpiece family karaoke kota bengkulu".

\section{TINJAUAN PUSTAKA}

\section{Strategi Pemasaran}

Menurut Kotler(2007:301) strategy pemasaran adalah suatu proses social dan manajerial yang didalamnyaindividu dan kelompok mendapatkan apa yang mereka butuhkan dan inginkan dengan menciptakan,menawarkan, dan mempertukarkan produk yang bernilai kepada pihak lain. Menurut David (2010:178) tiga factor yang menyebabkan terjadinya perubahan strategi dalam pemasaran yaitu :

1. Daur hidup produk

2. Posisi persaingan perusahaan di pasar

3. Situasi ekonomi

Menurut Rangkuti (2015:210) dalam pemasaran terdapat enam konsep yang merupakan dasar pelaksanaan kegiatan pemasaran suatu organisasi yaitu: Konsep Produk, Konsep Penjualan, Konsep Pemasaran, Konsep Pemasaran Sosial, dan Konsep Pemasaran Global.

\section{Pengertian Pemasaran}

America Marketing Association (AMA) menawarkan definisi formal berikut: pemasaran adalah suatu fungsi organisasi dan serangkaian proses untuk mengelola hubungan pelanggan dengan cara yang menguntungkan organisasi dan pemangku kepentingannya. menangani proses pertukaran ini membutuhkan banyak kerja dan keterampilan (Kotler 2007:5). Para manajer terkadang menganggap pemasaran sebagai "seni menjual produk", namun banyak orang terkejut ketika mendengar bahwa menjual bukanlah bagian terpenting dari pemasaran, Menjual hanyalah ujung dari gunung es pemasaran.

Menurut Drucker (2008:75), ahli teori manajemen terkemuka menjelaskannya sebagai berikut : selalu ada kebutuhan akan penjualan. Namun tujuan dari pemasaran adalah membuat penjualan berlimpah. Tujuan pemasaran adalah mengetahui dan memahami pelanggan dengan baik sehingga produk atau jasa bisa sesuai dengan kebutuhannya sehingga terjual sendiri. Idealnya, pemasaran harus menghasilkan seorang pelanggan yang siap untuk membeli. Dengan demikian yang dibutuhkan hanyalah memastikan produk dan jasa tersedia.

\section{Bauran Pemasaran (Marketing Mix)}

Kotler (2007:211) mendefinisikan bauran pemasaran sebagai seperangkat alat pemasaran yang digunakan perusahaan untuk tujuan pemasarannya dan pasar sasaran. 
Bauran pemasaran merupakan kumpulan strategi yangterdiri dari 4P yaitu produk (Product), harga (Price), saluran distribusi (Place), dan promosi (Promotion). Keempat bauran tersebut dijelaskan sebagai berikut:
1. Produk (product)
2. Harga (price)
3. distribusi (place)
4. Promosi (promotion)

Promosi adalah suatu aktifitas yang menyampaikan manfaat produk untuk menunjang konsumen atau pelanggan dalam pembeliannya untuk memujuk pelanggan sasaran untuk membeli. Menurut Santanto (2013:110) pakar marketing mix yaitu Lovelock dan Wright mengembangkan bauran pemasaran menjadi integrated servase management dengan menggunakan pendekatan 8P, yaitu: product elements, place, cyberspace, and time, promotion and education, price and other user outlays, process, productivity and quality, people, and physical evidence diantaranya :

1. Product elements

2. Place, cyberspace, and time

3. Promotion and education

4. Price and other user outlays

5. Process

6. Productivity and quality,produktivitas

7. People

8. Physical evidence

\section{Macam-Macam Strategi Pemasaran}

Pengertian strategi pemasaran merupakan suatu proses seleksi pasar yang ditarget, penentuan posisi bersaing dan pengembangan suatu bauran yang efektif untuk mencapai serta melayani konsumen yang telah ditarget. Menurut Assauri (2008:163), macammacam strategi pemasaran dapat diklasifikasikan menjadi tiga macam sebagai berikut :

1. Strategi pemasaran tidak membeda-bedakan pasar atau undifferentiated marketing merupakan strategi pemasaran yang tidak membeda-bedakan konsumen berdasarkan suatu kriteria khusus artinya kebutuhan konsumen secara umum tanpa membedabedakan.

2. Strategi pemasaran membeda-bedakan pasar atau differntiated marketing adalah perusahaan melakukan pengklasifikasian berdasarkan suatu kriteria tertentu

Strategi pemasaran pasar terkonsentrasi atau concentrated marketing adalah perusahaan memfokuskan pemasaran produknya dalam beberapa kelompok konsumen dengan mempertimbangkan keterbatasan sumberdaya perusahaan.

\section{Siklus Hidup Produk}

Pengertian Siklus hidup produk menurut Griffin (2002:234) adalah sebagai berikut : "Siklus hidup produk (product life cycle) adalah suatu model yang menunjukkan bagaimana volume penjualan dapat berubah selama hidup suatu produk". Pengertian lain seperti yang dikemukakan oleh Mulyadi (2001:36) adalah sebagai berikut: "Siklus hidup produk (product life cycle) adalah waktu suatu produk mampu memenuhi kebutuhan customer, sejak lahir sampai diputuskan dihentikan pemasarannya ". Btocher 
et al. (2000:166) menyatakan bahwa siklus hidup produk dipandang atas dua aspek, yaitu : a. Biaya selama siklus hidup produk (cost life cycle)

a. Penjualan selama siklus hidup produk (sales life cycle)

Bila dikatakan bahwa produk mempunyai suatu siklus hidup, ini akan sama saja dengan mengatakan bahwa sebuah produk memiliki siklus hidup berarti menegaskan empat hai seperti yang dikemukakan oleh Philip Kotler (2002:347) yaitu :

1. Produk memiliki umur yang terbatas.

2. Penjualan produk melalui beibagai tahap yang berbeda, masing-masing memberikan tantangan, peluang dan masalah yang berbeda bagi penjual.

3. Laba naik dan turun pada berbagai tahap yang berbeda selama siklus hidup produk.

4. Produk memerlukan strategi pemasaran, keuangan, manufaktur, pembelian dan sumber daya manusia yang berbeda dalam tiap tahap siklus hidupnya.

\section{Analisis Matrik Internal-Eksternal}

Menurut Rangkuti (2001:42) matrik Internal Eksternal merupakan sebuah model yang dikembangkan dari model General Electric, parameter yang digunakan meliputi parameter kekuatan internal perusahaan dan pengaruh eksternal yang dihadapi perusahaan. Tujuan penggunaan model ini adalah untuk memperoleh strategi bisnis di tingkat korporasi yang lebih detail. Identifikasi 9 sel strategi perusahaan menurut Rangkuti (2001:42) pada prinsipnya ke sembilan sel tersebut dapat dikelompokkan menjadi tiga strategi utama, yaitu:

1. Growth Strategy merupakan pertumbuhan perusahaan itu sendiri (sel 1, 2, dan 5) atau upaya diversifikasi (sel 7 dan 8) .

2. Stability Strategy yaitu strategi yang diterapkan tanpa mengubah arah strategi yang telah diterapkan.

3. Retrencment Strategy yaitu usaha memperkecil atau mengurangi usaha yang dilakukan perusahaan.

Mendirikan suatu usaha tidak lepas dari kendala yang muncul dari dalam maupun luar lingkungan sekitar usaha yang menyebabkan terjadinya persaingan, agar dapat bertahan dalam hal ini diperlukan sebuah "strategi ". Strategi adalah suatu alat yang direncana dari fungsi manajemen yang dimiliki suatu usaha atau perusahaan untuk mengalokasikan segala sumber daya yang ada agar dapat mengembangkan kopentensi. Strategi bisnis dapat membantu dalam memperbaiki strategi pemasara suatu usaha salah satunya masterpiece family karaoke kota bengkulu dengan cara memanfaatkan kinerja manajer dari fungsi-fungsi kegiatan manajemen disuatu perusahaan, misalnya strategi customer intimacy (keunggulan terhadap pelanggan), strategi operasional, strategi keunggulan produk. Untuk menentukan strategi-strategi tersebut melakukan analisis matrik internal eksternal, dimana analisis ini dapat memaksimalkan kekuatan dan peluang yang ada serta meminimalisasikan kelemahan dan ancaman yang ada dimiliki suatu usaha.

\section{METODE PENELITIAN}

Jenis Penelitian yang digunakan adalah deskripsi analisis. Menurut David (2010:122)

Penelitian deskripsi analisis adalah penelitian yang digunakan untuk mendapatkan data 
dari tempat tertentu. Penelitian ini bertujuan menjelaskan strategi paling tepat yang bisa digunakan oleh masterpiece family karaoke kota bengkulu melalui analisis matrik internal eksternal. Data yang digunakan dalam penulisan ini adalah data primer. Data primer dalam penulisan ini didapat dari hasil kuisioner penulis dengan pihak perusahaan, masterpiece family karaoke kota bengkulu dan konsumennya.

\section{Metode Pengambilan Sampel}

Data yang digunakan dalam penelitian, dapat berupa populasi atau sampel. Populasi adalah totalitas dari semua objek atau individu yang memiliki karakteristik tertentu, jelas dan lengkap. Populasi dalam penelitian ini adalah seluruh perusahaan sejenis di kota bengkulu. Sedangkan sampel adalah bagian dari jumlah dan karakteristik yang dimiliki oleh populasi tersebut (sugiyono, 2014:297). Sampel pada penelitian ini adalah karyawan masterpiece family karaoke kota bengkulu dan konsumennya. Jumlah sampel yang dipilih sebanyak IFAS $=25$ orang dengan pengambilan sampel secara acak dengan divisi ataupun jadwal yg berbeda maka dari itu sampel yg diambil 50\% dari karyawan dengan jumlah 25 orang per shit malam dan EFAS $=50$ orang, karakteristik konsumen laki-laki dan perempuan dengan kriteria konsumen dengan jumlah 50 orang per shift malam dalam proses negosiasi antara karyawan dengan konsumen yang telah ditentukan untuk pilihan paket contoh : paket ulang tahun, paket valentine days,paket imlek dan sebagainya. Dan jenis ruangan contoh : ruangan solitaire, vvip, vip, deluxe, larg, medium, dan small, yang tersedia pada perusahaan jadi responden pada penelitian ini berjumlah 75 orang

\section{Metode Pengumpulan Data}

Metode pengumpulan data dilakukan dengan menggunakan kuisioner. Menurut Sugiyono (2014:308) kuisioner adalah suatu teknik pengumpulan data dengan bantuan suatu daftar pertanyaan yang memperoleh data dari responden. Dengan pemilihan jawaban (Rangkuti, 2017:204 ) sebagai berikut :

Tabel 2. Tabel Bobot Jawaban Faktor Internal Eksternal

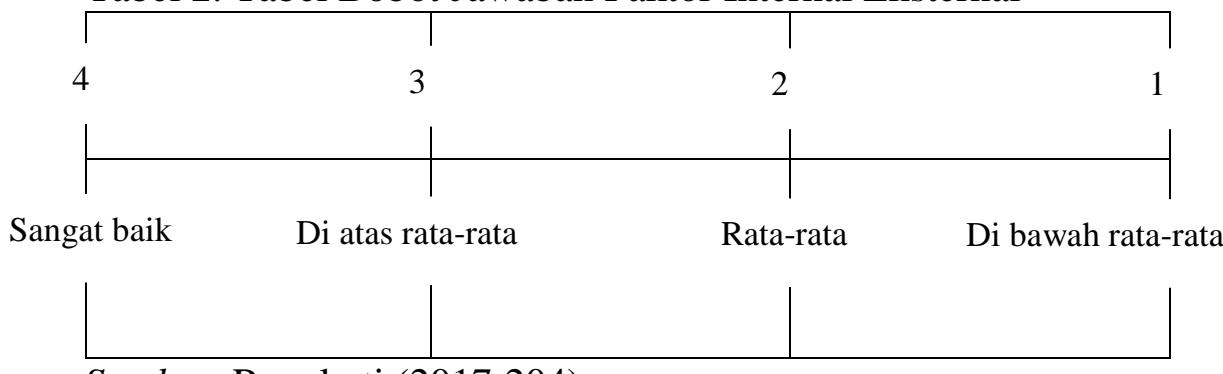

Sumber: Rangkuti (2017:204)

Tabel diatas menjelaskan bahwa:

1. Jawaban sangat baik diberi skor 4 .

2. Jawaban di atas rata-rata diberi skor 3 .

3. Jawaban rata-rata diberi skor 2 .

4. Jawaban dibawah rata-rata diberi skor 1 .

\section{Metode Analisis}

Metode analisis yang digunakan dalam penelitian ini adalah menggunakan matrik faktor strategi internal eksternal. 


\section{HASIL PENELITIAN DAN PEMBAHASAN}

\section{a. Karakteristik Data Responden}

Tabel 5. Karakteristik Data Responden Berdasarkan Jenis Kelamin

$\begin{array}{lll}\text { Jenis Kelamin } & \begin{array}{l}\text { Jumlah Responden } \\ \text { (Orang) }\end{array} & \begin{array}{l}\text { Presentase } \\ (\%)\end{array} \\ \text { Laki-Laki } & 37 & 49,33 \\ \text { Perempuan } & 38 & 50,67 \\ \text { Jumlah } & 75 & 100\end{array}$

Sumber: Hasil penelitian, data diolah 2018

Dari tabel 7 di atas di ketahui bahwa perempuan sebesar 50,67\% lebih banyak dibandingkan laki-laki sebesar 49,33\%, hal ini karena memang pelanggan perempuan cenderung lebih konsumtif jika dibandingkan pelanggan laki laki.

b. Karakteristik Data Respon Berdasarkan Umur

Usia responden dibagi ke dalam dua kelompok. Berdasarkan data dari lapangan, diperoleh kelompok responden seperti pada tabel 8.

\begin{tabular}{lll}
\multicolumn{2}{c}{ Tabel 6. Karakteristik Responden Berdasarkan Umur } \\
Umur & Jumlah & Persentase \\
(Tahun) & (Orang) & $(\%)$ \\
17-35 Tahun & 50 & 60 \\
36-60 Tahun & 25 & 40 \\
Jumlah & 75 & 100
\end{tabular}

Sumber: Hasil penelitian, data diolah 2018

Tabel di atas di ketahui bahwa umur dari 17-35 tahun sebesar 60\% lebih banyak dibandingkan yang berumur 36-60 tahun sebesar 40\%, hal ini dikarenakan karakteristik konsumen laki-laki dan perempuan per shift siang dan shift malam di dominasi harga paket yang diberikan berbeda.

c. Karakteristik Data Responden Berdasarkan Perkerjaan

Perkerjaan responden dibagi ke dalam 4 kelompok. Berdasarkan data dari lapangan, diperoleh kelompok responden seperti pada tabel 7.

Tabel 7. Karakteristik Responden Berdasarkan Pekerjaan

$\begin{array}{lll}\text { Pekerjaan } & \begin{array}{l}\text { Jumlah } \\ \text { (Orang) }\end{array} & \begin{array}{l}\text { Persentase } \\ (\%)\end{array} \\ \text { Mahasiswa/Pelajar } & 34 & 45,3 \\ \text { Swasta } & 20 & 26,7 \\ \text { PNS } & 15 & 20 \\ \text { Lainnya } & 6 & 8 \\ \text { Jumlah } & 75 & 100\end{array}$

Sumber: Hasil penelitian, data diolah 2018

Tabel di atas di ketahui bahwa jumlah responden yang berprofesi sebagai mahasiswa/pelajar 45,3\% lebih banyak dari responden yang berprofesi sebagai swasta 
sebesar $26,7 \%$, PNS sebesar $20 \%$ dan profesi lainnya sebesar $8 \%$, hal ini dikarenakan peminat sarana hiburan keluarga di dominasi swasta.

\section{Analisis Matrik Internal Ekternal untuk Strategi Pemasaran Masterpiece family karaoke kota Bengkulu}

Tabel 8. Faktor Strategi Internal

\begin{tabular}{|c|c|c|c|c|}
\hline No & Kekuatan & $\begin{array}{l}\text { Nilai } \\
\text { Bobot }\end{array}$ & Rating & Skor \\
\hline 1 & $\begin{array}{l}\text { Mempunyai pencitraan nama } \\
\text { perusahaan yang baik }\end{array}$ & 0,21 & 3 & 0,63 \\
\hline 2 & $\begin{array}{llll}\begin{array}{l}\text { Fasilitas yang tesedia } \\
\text { memadai }\end{array} & \text { sudah } \\
\end{array}$ & 0,20 & 3 & 0,6 \\
\hline 3 & lokasi yang strategis & 0,21 & 3 & 0,63 \\
\hline 4 & $\begin{array}{l}\text { Harga yang ditawarkan } \\
\text { terjangkau bagi masyarakat }\end{array}$ & 0,19 & 2 & 0,38 \\
\hline 5 & $\begin{array}{l}\text { Tingkat kepercayaan masyarakat } \\
\text { terhadap perusahaan sangat baik }\end{array}$ & 0,16 & 2 & 0,32 \\
\hline \multicolumn{2}{|c|}{ Kelemahan } & & & \\
\hline 1 & $\begin{array}{l}\text { Memerlukan modal yang besar } \\
\text { untuk mengembangkan usaha }\end{array}$ & 0,18 & 2 & 0,36 \\
\hline 2 & $\begin{array}{l}\text { Kesejateraan karyawan kurang } \\
\text { terjamin }\end{array}$ & 0,19 & 2 & 0,38 \\
\hline 3 & $\begin{array}{l}\text { Terdapat tempat parkiran yang } \\
\text { kurang efisien }\end{array}$ & 0,19 & 1 & 0,19 \\
\hline 4 & Sumber daya yang masih kurang & 0,21 & 1 & 0,21 \\
\hline 5 & $\begin{array}{l}\text { Adanya resiko suku cadang } \\
\text { barang jumlah yang kurang dalam } \\
\text { perusakan sound system }\end{array}$ & 0,19 & 1 & 0,19 \\
\hline \multicolumn{4}{|c|}{ Total Skor Faktor Strategi Internal } & 3,89 \\
\hline
\end{tabular}

Sumber: Hasil Penelitian 2018

Dari hasil penelitian diatas, maka diperoleh hasil rekapitulasi jumlah jawaban kuisioner untuk faktor internal sebagai berikut: 
Tabel 9. Rekapitulasi Jumlah Jawaban Kuesioner Untuk Faktor Internal

\begin{tabular}{|l|l|l|l|l|l|}
\hline \multirow{2}{*}{ No } & Kekuatan (Strenghts) & \multicolumn{4}{|l|}{ Responden } \\
\cline { 2 - 7 } 1 & SB & AR & RR & BR \\
\hline 2 & $\begin{array}{l}\text { Mempunyai pencitraan nama } \\
\text { perusahaan yang baik }\end{array}$ & 25 & 0 & 0 & 0 \\
\hline 3 & Lokasi yang strategis & 22 & 3 & 0 & 0 \\
\hline 4 & $\begin{array}{l}\text { Harga yang ditawarkan terjangkau } \\
\text { bagi masyarakat }\end{array}$ & 15 & 10 & 0 & 0 \\
\hline 5 & $\begin{array}{l}\text { Tingkat kepercayaan masyarakat } \\
\text { terhadap perusahaan sangat baik }\end{array}$ & 17 & 8 & 0 & 0 \\
\hline Kelemahan (Weaknesses) & Responden & 0 & 0 \\
\hline 1 & $\begin{array}{l}\text { Memerlukan modal yang besar untuk } \\
\text { mengembangkan usaha }\end{array}$ & 0 & 14 & 11 & 0 \\
\hline 2 & $\begin{array}{l}\text { Kesejateraan karyawan kurang } \\
\text { terjamin }\end{array}$ & 0 & 11 & 11 & 3 \\
\hline 3 & $\begin{array}{l}\text { Terdapat tempat parkiran yang } \\
\text { kurang efisien }\end{array}$ & 0 & 12 & 9 & 4 \\
\hline 4 & Sumber daya yang masih kurang & 0 & 14 & 11 & 0 \\
\hline 5 & $\begin{array}{l}\text { Adanya resiko suku cadang barang } \\
\text { jumlah yang kurang dalam kerusakan } \\
\text { sound system }\end{array}$ & 0 & 10 & 2 & 2 \\
\hline
\end{tabular}

Sumber: Hasil Penelitian 2018

Tabel 10. Faktor Strategi Eksternal

\begin{tabular}{|l|l|l|l|l|}
\hline No & Peluang Nilai & Rating & Skor \\
\hline 1 & $\begin{array}{l}\text { Hubungan baik dengan } \\
\text { konsumen }\end{array}$ & 0,27 & 3 & 0.81 \\
\hline 2 & $\begin{array}{l}\text { Jumlah penduduk yang terus } \\
\text { mengalami pertambahan }\end{array}$ & 0,24 & 3 & 0,72 \\
\hline 3 & $\begin{array}{l}\text { Bertambah majunya } \\
\text { teknologi di masterpiece } \\
\text { family karaoke kota } \\
\text { Bengkulu }\end{array}$ & 0,24 & 2 & 0,48 \\
\hline 4 & $\begin{array}{l}\text { Pola hidup yang praktis dari } \\
\text { masyarakat }\end{array}$ & 0,24 & 2 & 0,48 \\
\hline
\end{tabular}




\begin{tabular}{|l|l|l|l|l|}
\hline \multicolumn{2}{|l|}{ Ancaman } & 2 & 0,34 \\
\hline 1 & $\begin{array}{l}\text { Tingkat pesaing semakin } \\
\text { ketat }\end{array}$ & 0,17 & 1 & 0,17 \\
\hline 2 & $\begin{array}{l}\text { Banyaknya masyarakat } \\
\text { menggunakan karaoke } \\
\text { rumahan }\end{array}$ & 0,17 & 1 & 0.20 \\
\hline 3 & $\begin{array}{l}\text { Perubahan faktor cuaca tidak } \\
\text { mendukung }\end{array}$ & 0,20 & 1 & 0,19 \\
\hline 4 & $\begin{array}{l}\text { Masuknya pesaing baru yang } \\
\text { sejenis }\end{array}$ & 0,19 & 1 & 0,48 \\
\hline 5 & $\begin{array}{l}\text { Perkembangan teknologi } \\
\text { yang belum di kuasai }\end{array}$ & 0,24 & 2 & $\mathbf{3 , 8 7}$ \\
\hline
\end{tabular}

Dari hasil penelitian diatas, maka diperoleh hasil rekapitulasi jumlah jawaban kuisioner untuk faktor internal sebagai berikut:

Tabel 11. Rekapitulasi Jumlah Jawaban Kuesioner Untuk Faktor Eksternal

\begin{tabular}{|c|c|c|c|c|c|}
\hline \multirow{2}{*}{ No } & \multirow{2}{*}{ Peluang } & \multicolumn{4}{|c|}{ Responden } \\
\hline & & SB & $\mathbf{A R}$ & $\mathbf{R R}$ & BR \\
\hline 1 & $\begin{array}{l}\text { Hubungan } \\
\text { konsumen }\end{array}$ & 50 & 0 & 0 & 0 \\
\hline 2 & $\begin{array}{l}\text { Jumlah penduduk yang terus } \\
\text { mengalami pertambahan }\end{array}$ & 24 & 26 & 0 & 0 \\
\hline 3 & $\begin{array}{l}\text { Bertambah majunya teknologi di } \\
\text { masterpiece family karaoke } \\
\text { Kota Bengkulu }\end{array}$ & 25 & 25 & 0 & 0 \\
\hline \multirow[t]{2}{*}{4} & $\begin{array}{l}\text { Pola hidup yang peraktis dari } \\
\text { masyarakat }\end{array}$ & 24 & 26 & 0 & 0 \\
\hline & Ancaman & \multicolumn{4}{|c|}{ Responden } \\
\hline 1 & Tingkat pesaing semakin ketat & 0 & 0 & 20 & 30 \\
\hline 2 & $\begin{array}{l}\text { Banyaknya masyarakat } \\
\text { menggunakan karaoke rumahan }\end{array}$ & 0 & 0 & 20 & 30 \\
\hline 3 & $\begin{array}{l}\text { Perubahan faktor cuaca tidak } \\
\text { mendukung }\end{array}$ & 0 & 0 & 30 & 20 \\
\hline 4 & $\begin{array}{l}\text { Masuknya pesaing baru yang } \\
\text { sejenis }\end{array}$ & 0 & 0 & 29 & 21 \\
\hline 5 & $\begin{array}{l}\text { Perkembangan tekhnologi yang } \\
\text { belum di kuasai }\end{array}$ & 0 & 3 & 37 & 10 \\
\hline
\end{tabular}

Sumber: Hasil penelitian 2018 
Dari hasil analisis faktor strategi internal dan eksternal, maka dapat disusun tabel matrik internal eksternal yang terdiri dari 9 sel strategi perusahaan. Masing-masing strategi memiliki karakteristik tersendiri dan hendaknya dalam implementasi strategi dilakukan secara bersama-sama dan saling mendukung satu sama lainnya. Matriks internal eksternal dilakukan dengan memasukkan total skor faktor strategi internal dan total skor faktor strategi eksternal. Perusahaan yang terletak pada sel 1, 2, 5, 7, dan 8 dalam kondisi tumbuh dan berkembang, sel 4 dan 5 dalam kondisi bertahan dan sel 3,6, dan 9 dalam kondisi panen.

Tabel 12. Faktor Strategi Internal

\begin{tabular}{|c|c|c|c|c|}
\hline No & Kekuatan & $\begin{array}{l}\text { Nilai } \\
\text { Bobot }\end{array}$ & Rating & Skor \\
\hline 1 & $\begin{array}{l}\text { Mempunyai pencitraan nama } \\
\text { perusahaan yang baik }\end{array}$ & 0,21 & 3 & 0,63 \\
\hline 2 & $\begin{array}{l}\begin{array}{l}\text { Fasilitas yang tesedia sudah } \\
\text { memadai }\end{array} \\
\end{array}$ & 0,20 & 3 & 0,6 \\
\hline 3 & lokasi yang strategis & 0,21 & 3 & 0,63 \\
\hline 4 & $\begin{array}{l}\text { Harga yang ditawarkan } \\
\text { terjangkau bagi masyarakat }\end{array}$ & 0,19 & 2 & 0,38 \\
\hline 5 & $\begin{array}{l}\text { Tingkat kepercayaan masyarakat } \\
\text { terhadap perusahaan sangat baik }\end{array}$ & 0,16 & 2 & 0,32 \\
\hline \multicolumn{2}{|c|}{ Kelemahan } & & & \\
\hline 1 & $\begin{array}{l}\text { Memerlukan modal yang besar } \\
\text { untuk mengembangkan usaha }\end{array}$ & 0,18 & 2 & 0,36 \\
\hline 2 & $\begin{array}{l}\text { Kesejateraan karyawan kurang } \\
\text { terjamin }\end{array}$ & 0,19 & 2 & 0,38 \\
\hline 3 & $\begin{array}{l}\text { Terdapat tempat parkiran yang } \\
\text { kurang efisien }\end{array}$ & 0,19 & 1 & 0,19 \\
\hline 4 & Sumber daya yang masih kurang & 0,21 & 1 & 0,21 \\
\hline 5 & $\begin{array}{l}\text { Adanya resiko suku cadang } \\
\text { barang jumlah yang kurang dalam } \\
\text { perusakan sound system }\end{array}$ & 0,19 & 1 & 0,19 \\
\hline \multicolumn{4}{|c|}{ Total Skor Faktor Strategi Internal } & 3,89 \\
\hline
\end{tabular}

Sumber: Hasil Penelitian 2018 
Tabel 13. Faktor Strategi Eksternal

\begin{tabular}{|c|c|c|c|c|}
\hline No & Peluang & $\begin{array}{l}\text { Nilai } \\
\text { Bobot }\end{array}$ & Rating & Skor \\
\hline 1 & $\begin{array}{l}\text { Hubungan baik dengan } \\
\text { konsumen }\end{array}$ & 0,27 & 3 & 0.81 \\
\hline 2 & $\begin{array}{l}\text { Jumlah penduduk yang terus } \\
\text { mengalami pertambahan }\end{array}$ & 0,24 & 3 & 0,72 \\
\hline 3 & $\begin{array}{l}\text { Bertambah majunya } \\
\text { teknologi di masterpiece } \\
\text { family karaoke kota } \\
\text { Bengkulu }\end{array}$ & 0,24 & 2 & 0,48 \\
\hline 4 & $\begin{array}{l}\text { Pola hidup yang praktis dari } \\
\text { masyarakat }\end{array}$ & 0,24 & 2 & 0,48 \\
\hline \multicolumn{5}{|c|}{ Ancaman } \\
\hline 1 & $\begin{array}{l}\text { Tingkat pesaing semakin } \\
\text { ketat }\end{array}$ & 0,17 & 2 & 0,34 \\
\hline 2 & $\begin{array}{lr}\text { Banyaknya } & \text { masyarakat } \\
\text { menggunakan } & \text { karaoke } \\
\text { rumahan } & \\
\end{array}$ & 0,17 & 1 & 0,17 \\
\hline 3 & $\begin{array}{l}\text { Perubahan faktor cuaca tidak } \\
\text { mendukung }\end{array}$ & 0,20 & 1 & 0.20 \\
\hline 4 & $\begin{array}{l}\text { Masuknya pesaing baru yang } \\
\text { sejenis }\end{array}$ & 0,19 & 1 & 0,19 \\
\hline 5 & $\begin{array}{l}\text { Perkembangan teknologi } \\
\text { yang belum di kuasai }\end{array}$ & 0,24 & 2 & 0,48 \\
\hline \multicolumn{4}{|c|}{ Jumlah skor faktor strategi eksternal } & 3,87 \\
\hline
\end{tabular}

Dari hasil analisis faktor strategi internal dan eksternal, maka dapat disusun tabel matrik internal eksternal yang terdiri dari 9 sel strategi perusahaan. Masing-masing strategi memiliki karakteristik tersendiri dan hendaknya dalam implementasi strategi dilakukan secara bersama-sama dan saling mendukung satu sama lainnya

Matriks internal eksternal dilakukan dengan memasukkan total skor faktor strategi internal dan total skor faktor strategi eksternal. Perusahaan yang terletak pada sel 1, 2, 5, 7, dan 8 dalam kondisi tumbuh dan berkembang, sel 4 dan 5 dalam kondisi bertahan dan sel 3,6, dan 9 dalam kondisi panen. Berikut ini merupakan hasil dari analisis matrik internal eksternal yang mana menunjukan adanya pengaruh faktor kekuatan, kelemahan, peluang, dan ancaman yang terjadi pada Masterpiece family karaoke kota bengkulu.

Dari hasil pengolahan data faktor strategi internal dan eksternal diperoleh total skor faktor strategi internal sebesar 3,89 dan total skor faktor strategi eksternal sebesar 3,87, maka masterpiece family karaoke kota bengkulu terletak pada sel 1 dengan menggunakan strategi pertumbuhan yaitu pertumbuhan dan konsentrasi melalui integrasi vertikal.Berdasarkan perhitungan dan gambar dari matrik internal eksternal di 
atas, dapat diketahui bahwa matrik internal eksternal memiliki hubungan yang erat dengan siklus hidup produk seperti gambar dibawah ini:

Gambar 7. Hubungan Siklus Hidup Produk dengan Matrik Internal Eksternal

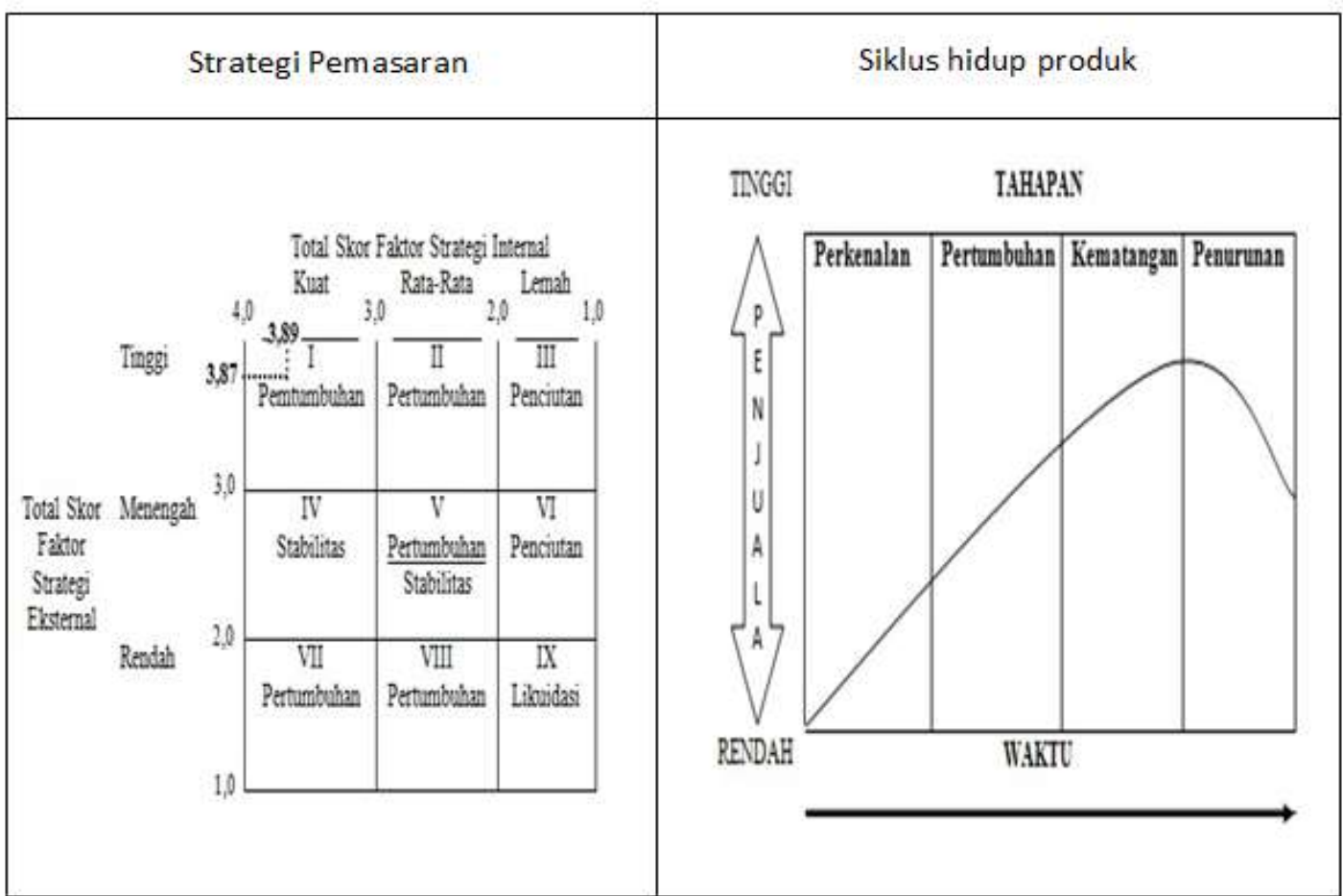

Berdasarkan perhitungan dan gambar matrik internal eksternal diatas dalam hubungannya dengan siklus hidup produk, dapat diketahui bahwa posisi produk masterpiece family karaoke kota Bengkulu dalam tahap pertumbuhan (growth). Pada tahap ini, produk mulai diterima oleh pasar dan penjualan tumbuh dengan cepat pada saat produk mulai mencapai pasar. Produsen mulai meraih laba besar dengan semakin banyaknya pelanggan (costumer) membeli produk mereka. Tetapi pada tahap ini pesaing atau kompetitor melihat peluang yang sangat besar dan mulai ikut masuk pasar. Beberapa pesaing mencoba untuk mempertajam penawaran mereka dengan memikat pasar dengan sasaran tertentu serta dengan menurunkan harga produk mereka.

\section{PEMBAHASAN}

Berdasarkan hasil penelitian yang telah dilakukan pada masterpiece family karaoke kota bengkulu dapat diartikan bahwa:

Identifikasi 9 sel strategi perusahaan menurut Rangkuti (2001:42) pada prinsipnya ke sembilan sel tersebut dapat dikelompokkan menjadi tiga strategi utama, yaitu:

1. Growth Strategy merupakan pertumbuhan perusahaan itu sendiri (sel 1,2, dan 5) atau upaya diversifikasi (sel 7 dan 8) .

2. Stability Strategy yaitu strategi yang diterapkan tanpa mengubah arah strategi yang telah diterapkan. 
3. Retrencment Strategy yaitu usaha memperkecil atau mengurangi usaha yang dilakukan perusahaan.

Perusahaan yang dianggap sukses adalah perusahaan yang mampu menghasilkan bisnis yang berada pada sel 1. Menurut Rangkuti (2001:42-46) untuk memperoleh penjelasan secara lebih detail mengenai kesembilan strategi yang terdapat pada sembilan sel matrik IE (internal,eksternal), maka dapat dijelaskan sebagai berikut:

\section{Strategi Pertumbuhan (Growth Strategy)}

Dari hasil faktor strategi internal dan eksternal, maka kekuatan yang miliki oleh masterpiece family karaoke kota bengkulu sebesar 2,56 sedangkan kelemahan 1,33, sehingga total skor faktor strategi internal sebesar 3,89. Peluang yang dimiliki strategi tersebut sebesar 2,49 dengan ancaman sebesar 1,38, sehingga total skor faktor strategi eksternal sebesar 3,87.

Gambar 8. Siklus Hidup Produk dengan Matrik Internal Eksternal

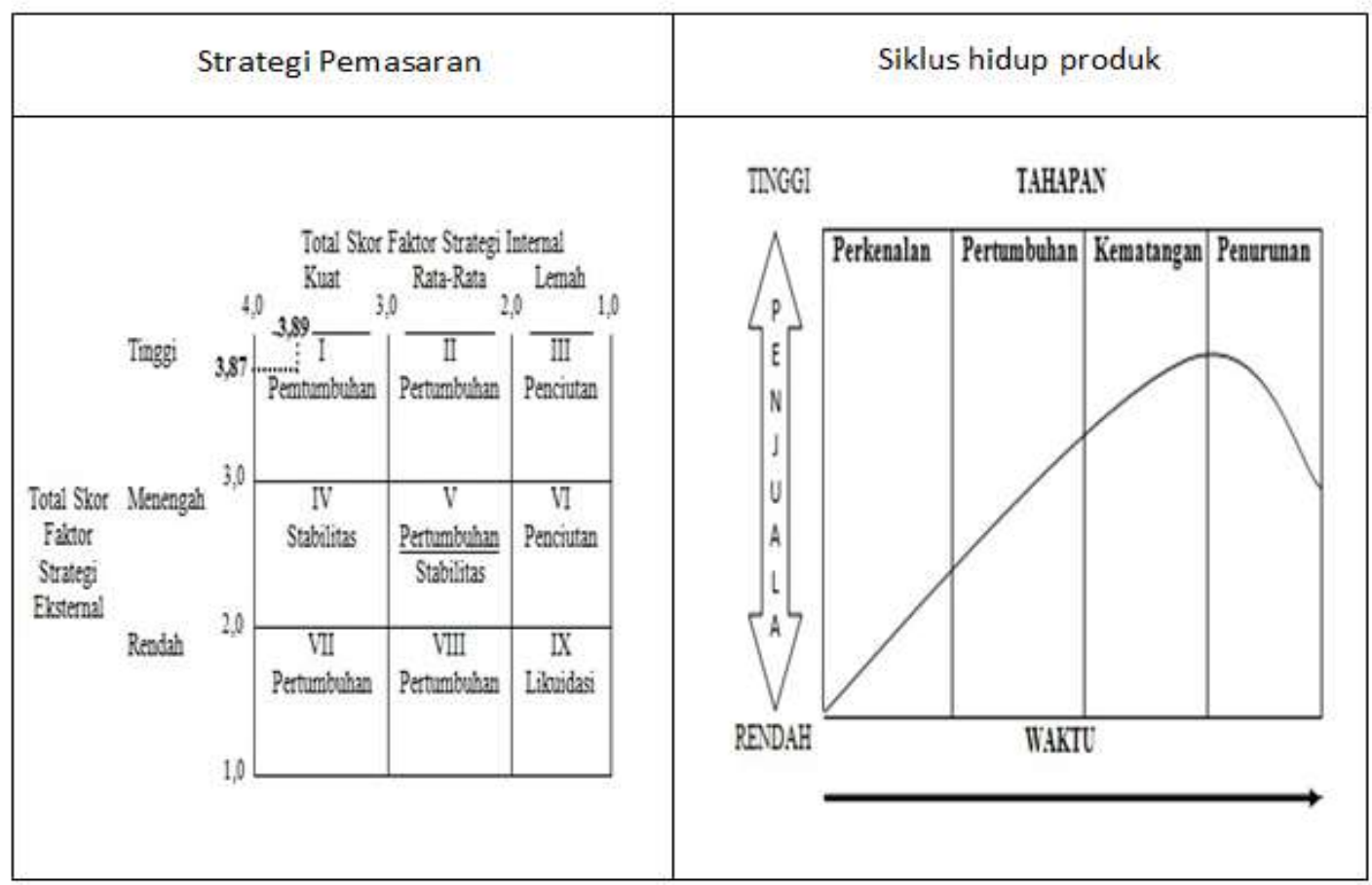

Sumber: Hasil penelitian 2018

Dalam usaha ini, menunjukan bahwa strategi pemasarannya adalah strategi pertumbuhan dengan konsentrasi melalui integrasi vertikal. Strategi ini dibuktikan berdasarkan usaha yang ada, yaitu dengan mengambil alih fungsi supplier dari produk makanan maupun minuman dengan memproduksi sendiri salah satu dari produk yang dipasarkan. Hal ini dilakukan untuk memperluas area usaha masterpiece family karaoke kota bengkulu. Strategi ini adalah strategi yang menguntungkan karena usaha tersebut memiliki peluang dan kekuatan dalam memajukan masterpiece family karaoke kota 
bengkulu. Matriks internal eksternal dilakukan dengan memasukkan seluruh total skor faktor strategi internal dan eksternal perusahaan.

\section{KESIMPULAN}

Berdasarkan dari hasil penelitian dan mengenai analisis matrix external dan internal pada masterpiece family karaoke kota bengkulu dapat disimpulkan bahwa hasil penelitian yang didapat pada masterpiece family karaoke kota Bengkulu berada pada Sel 1 dalam hal ini menunjukan situasi yang sangat menguntungkan perusahaan agar dapat memanfaatkan peluang yang ada. Strategi yang harus digunakan dalam kondisi ini yaitu strategi pertumbuhan dan konsentrasi melalui integrasi vertikal.

1. Kekuatan yang dimiliki oleh masterpiece family karaoke kota bengkulu adalah penetapan harga sudah sesuai dengan kondisi pasar, fasilitas yang tesedia sudah sesuai, jalan menuju lokasi memungkinkan untuk dilalui semua jenis kendaraan, saluran distribusi sangat berperan dalam meningkatkan jumlah penjualan, dan memiliki sumberdaya yang berkualitas.

2. Kelemahan yang dimiliki oleh masterpiece family karaoke kota bengkulu adalah terdapat tempat parkiran yang kurang efisien, dan sumber daya yang masih kurang.

3. Peluang yang dimiliki oleh masterpiece family karaoke kota bengkulu adalah hubungan baik dengan konsumen, jumlah penduduk yang terus mengalami pertambahan, bertambah majunya teknologi yang ada di masterpiece di kota bengkulu, dan pola hidup yang praktis dari masyarakat.

4. Ancaman yang dimiliki oleh masterpiece family karaoke kota bengkulu adalah perubahan cuaca yang sering berubah, masuknya pesaing baru yang sejenis, dan banyaknya masyarakat menggunakan karaoke rumahan.

\section{SARAN}

Dalam mengembangkan Masterpiece family karaoke kota bengkulu ada beberapa saran berdasarkan hasil pada analisis Matrik internal eksternal, sebagai berikut:

1. Masterpiece family karaouke kota bengkulu harus dapat menggunakan seluruh kekuatan dalam memanfaatkan peluang yang timbul.

2. Dalam membangun usahanya hendaklah menerapkan strategi berdasarkan analisis Matrik internal eksternal.

3. Masterpiece family karaoke kota bengkulu harus mampu mempromosikan produknya dengan lebih menarik serta mampu memberikan inovasi yang baru dan meningkatkan kreatifitas dalam menciptakan produknya seperti menu makanan, minuman yang unik dan menarik.

4. Masterpiece bengkulu memberikan informasi kepada konsumen tentang menggunakan aplikasi dari handphone play store Masterpiece KTV untuk mempermudah pencarian lagu dari player masterpiece family karaoke kota bengkulu 


\section{DAFTAR PUSTAKA}

Et, al, Btocher. 2000. Strategi Pemasaran. Erlangga. Jakarta. . 2001. Teknik Membedah Kasus Analisis Bisnis. PT Gramedia Pustaka Utama:

Jakarta.

Griffin. 2002. Strategi Pemasaran. Erlangga. Jakarta.

Kotler, Philip. 2007. ManajemenPemasaran. Jilid I. upper Saddle River.new Jersey.

Assauri. 2008. Strategi Pemasaran. Erlangga. Jakarta

Drucker, Peter F. 2008. Pengantar Manajemen. Pustaka Binaman Pressindo. Jakarta.

David, Fred R. 2010. Manajemen Strategi. Salemba Empat. Jakarta

Sugiyono. 2010. Metodologi Penelitian Bisnis. Alfabeta. Jakarta.

Widyatmini. 2012. “ Analisis Matrik Internal Eksternal Pada Strategi Pemasaran Produk Pada CV. Turangga Mas Motor “. Tesis. Fakultas Ekonomi Universitas Bengkulu. Bengkulu

Santanto. 2013. Strategi pemasaran. Alfabeta: Bandung.

Sugiyono. 2014. Metode Penelitian Kuantitatif Kualitatif dan R\&D. Alfabeta: Bandung

Rangkuti. 2015. Strategi pemasaran.Salemba Empat. Jakarta.

. 2017. Teknik Membedah Kasus Analisis Bisnis. PT Gramedia Pustaka Utama: Jakarta. 